Matthews P \& Poyner C, The experience of living in deprived neighbourhoods for LGBT+ people - making home in difficult circumstances, Environment and Planning A, 51 (7), pp. 1499-1515. Copyright The Authors 2019. Reprinted by permission of SAGE Publications.

\title{
The experience of living in deprived neighbourhoods for LGBT+ people - making home in difficult circumstances
}

Dr Peter Matthews

Senior Lecturer in Social Policy, University of Stirling

Stirling, FK9 4LA, UK

Peter.matthews@stir.ac.uk

Mr Chris Poyner

Research Assistant, University of Birmingham

\begin{abstract}
Research in urban studies on lesbian, gay bisexual and trans (LGBT+) people and their housing choices has focused on economic choices and the role of exclusion, or conversely higher household disposable income, in residential location. Evidence on lived experiences has focused on residence in so-called "gaybourhoods" with high concentrations of non-heterosexual households, or experiences within the home. Contrasting to this scholarship, in this paper we focus on LGBT+ people who live in socially-rented housing in deprived neighbourhoods that are geographically, socially and economically marginal. Our evidence shows how complex experiences of exclusion for LGBT+ people, not always directly connected to their sexual or gender identity led to individuals living in these neighbourhoods. Using the theoretical approach of housing pathways, we further suggest that these neighbourhoods offer limited affordances for wellbeing for LGBT+ individuals that need to be recognised by housing and other service providers. We also argue that mainstream housing and urban studies needs to use sexual and identity as a category of analysis in research so we can better understand the lived experiences of non-heterosexual individuals and households.
\end{abstract}

Keywords: LGBT+, housing, neighbourhood deprivation; housing pathways; gentrification

\section{Introduction}

Over recent decades many countries in the industrialised world have been transformed in their attitudes towards same-sex relationships and transgender identities. In England and Wales, 2017 marked the $50^{\text {th }}$ anniversary of the decriminalisation of sex, in private, between two men aged over 21. Despite this progress, there remains a concern that people who identify as lesbian, gay, bisexual or transgender $\left(\mathrm{LGBT}+{ }^{1}\right)$ are subject to exclusion within society, such as lower educational attainment due to bullying, or higher rates of homelessness (Uhrig, 2015; Ecker, 2016). Despite an awareness that LGBT+ people might continue to be excluded from society, or suffer the impacts of past exclusion on their lives now, urban studies scholarship has particularly framed experiences of LGBT+ people within narratives of gentrification and the links between gay, male commodification and neighbourhood change (Castells, 1983; Lauria and Knopp, 1985). On the one hand, the historic exclusion of lesbians and gays, and the difficulty of one-person households raising mortgage finance, is recognised as one of the reasons "gaybourhoods" emerged, particularly in the USA (Ghaziani, 2014). Similarly, the need for political representation, and to collocate around commercial services that were welcoming to queer lifestyles (bars, cafes, bookshops) are recognised as drivers for the concentration of LGBT+ people in certain areas of cities (Ghaziani, 2014). On the other hand, gay men are seen as first-wave gentrifiers, sometimes in thinly-veiled homophobic accounts, and part of 
Florida's "creative class" (Florida and Mellander, 2010; Castells, 1983; Andersson, 2019, online preprint). This led Gorman-Murray to raise the question in 2006: 'Why are gay men considered to be gentrifiers par excellence, with growing mainstream fascination about how they make home?' (Gorman-Murray, 2006: 66)

Other research in human geography, and associated disciplines, has focused on the processes by which LGBT+ people make home as an extension of their identity (Pilkey, 2014) and also how home as a blurring of the private and public offered a space of freedom for LGBT+ people as families of choice (Valentine et al., 2003; Donovan et al., 2004; Gorman-Murray, 2006). Such research rarely places the home, and the affordances it provides for a person or household, in a wider neighbourhood. Recognising these two strands of scholarship, this paper presents evidence from the lives of LGBT+ people in economically and socially marginalised neighbourhoods (Wacquant, 2008), known as deprived neighbourhoods within UK urban policy. These are not neighbourhoods with a high concentration of non-heterosexual, non-cisgender households, but they have also been the subject of considerable scholarship trying to understand the problems of such neighbourhoods and their causes (see, for example: Bailey and Livingston, 2008; Rae, 2012; Robson et al., 2008; Galster et al., 2000) or critical accounts focusing on the economic and social inequalities that marginalise such places (see, for example: Wacquant, 2008; Slater, 2013). The specific contribution of this paper is to bring this literature on marginal neighbourhoods that largely ignores the lives of LGBT+ people, together with evidence of the lived experience of LGBT+ people. This also adds to our understanding of the lives of LGBT+ people who are more economically and socially marginal and have very few housing choices.

\section{Residential choice and economic explanations of LGBT+ residential choice}

One of the key causal mechanisms suggested for non-heterosexual people ending up concentrated in particular neighbourhoods, is their limited household incomes, due to socio-economic exclusion and greater likelihood of being single, limiting housing choices. Such an explanation foregrounds economic causes. For example, in the US where very low-cost owner-occupation remains a key route into housing for economically marginal groups, LGBT+ households were widely recognised as firstwave gentrifiers (Castells, 1983; Ghaziani, 2014; Lauria and Knopp, 1985), where the investment of sweat-equity led to the collective upgrading of neighbourhoods (see, for example: Doan and Higgins, 2011). In these contexts, social housing provision is extremely minimal, very marginalised and stigmatised tenure, although there are higher concentrations of public housing in some US urban centres.

In a northern European context, the predominant form of affordable housing has been housing built by public authorities for affordable rent. Even in a country such as the UK, although the total stock of socially-rented housing continues to fall, it is still a tenure where those in low incomes can find a home at an affordable rent. In Scotland, such housing is called social housing, with rents limited in law and regulated by a national regulator, and subsidised by construction grants. It is let either by non-profit charitable housing associations or by local councils. Housing is allocated according to need, with individuals and households classed as homeless (in Scotland this is a more expansive definition than anywhere else in the world (Watts, 2014)) being prioritised for such housing. In Scotland, the ending of the Right-to-Buy policy, which gave social housing tenants the right to buy their homes off their landlords at a substantial discount, and continued capital investment in new homes, has led to the proportion of households living in social housing stabilising at 23 per cent since 2007 (Scottish Government, 2017a). Thus, it is likely that a household in housing need and with a low income, will be housed in social housing. 
Such housing is often geographically marked within towns and cities due to both urban and building design, as with the "housing projects" in a North American context. Substantial state-led housebuilding programmes in the post-war period led to most northern European countries having extremely large estates of social housing, often in peripheral suburban locations (Dekker and Van Kempen, 2004). With resident populations badly hit by economic restructuring from the early $1970 \mathrm{~s}$ onwards, as well as problems with housing management, such neighbourhoods became a major urban policy problem from the 1980s onwards (Dekker and Van Kempen, 2004; Hall, 1997; Tunstall and Coulter, 2006). Regeneration policies have led to the demolition of large amounts of housing in many estates, to diversify the housing tenure and reduce the concentration of individual and household deprivation produced by the concentrated social housing (Cheshire, 2009; Tunstall and Lupton, 2010). However, concentrations of single-tenure estates still dominate the urban geography of many cities, and in the UK outside of London, these are predominantly in suburban locations (Lawless, 2011).

The peripheral location of such neighbourhoods, local economic decline, and issues with poor quality housing that only those in greatest housing need are housed in, have led many of these areas to become very deprived, with a considerable proportion of residents experiencing individual problems, compounded by difficulties with managing the local environment (Hall, 1997). Across the UK, the terminology 'deprived neighbourhoods' is used in policy to define such neighbourhoods so they can be targeted for specific policy intervention and investment. The neighbourhoods are identified through regularly updated indices of multiple deprivation, bringing together a wide range of administrative data covering: income-related welfare benefits; employment levels; education; health; crime; and housing quality (Noble et al., 2006). In Scotland, the Scottish Index of Multiple deprivation (SIMD) divides the country into 6,976 datazones with an average population of 1,000. These are ranked from 1 (most deprived) to 6,976 (least deprived). Analysis by the Scottish Government identifies that the bottom quintile of datazones, are particularly marked by concentrated socio-economic deprivation (Scottish Executive, 2005; Scottish Government, 2016a). When a neighbourhood is described as "deprived" it is commonly made up of a number of contiguous datazones in the bottom quintile, following what we might expect from Tobler's law. Calculations by one of the authors of this paper suggest that two-thirds of households in social housing in Scotland are in the most deprived 15 per cent of datazones, demonstrating how the concentrated location of social housing concentrates populations in certain neighbourhoods (Matthews and Besemer, 2015).

Within this context of a mixed economy of housing, with substantial provision of social housing, we can surmise that socially and economically excluded LGBT+ people are likely to find themselves in social housing, which is likely to be in a deprived neighbourhood. Scottish Government analysis shows that a disproportionate number of non-straight people do live in most deprived neighbourhoods (Scottish Government, 2017b; Matthews and Besemer, 2015). Further analysis of earlier data suggests that these non-heterosexual individuals are older than their heterosexual neighbours, more likely to be single, and more likely to be in ill-health (Matthews and Besemer, 2015). This data supports the contention that, before recent legal and social advances, it was likely non-heterosexual people experienced exclusion in their lives - from their families of origin (Valentine et al., 2003), from education (Rivers and Cowie, 2006), or from employment - which limited their life chances and their housing choices (Uhrig, 2015). The lack of legal recognition of same-sex relationships (until 2005 in the UK) prevented people forming long-term relationships with the legal benefits of marriage, including access to mortgage finance, further limiting their housing choices (Doan and Higgins, 2011). 
As a result of these differing urban processes, in Scotland, we have an example of LGBT+ residence patterning that does not fit into current narratives within the research that focus on "gaybourhoods", or even the homonormative lifestyles of lesbian and gay couples living in affluent suburbs (Ghaziani, 2014). This leaves us with the research questions that frame the rest of this paper:

- How did LGBT+ people end up living in deprived neighbourhoods in Scotland?

- What is their experience of living in deprived neighbourhoods?

The second of these research questions is important because analysis of social attitudes in Scotland shows that residents of deprived neighbourhoods are less likely to be accepting of same-sex relationships compared to the rest of Scotland. For example, Scotland has seen a decline in the belief that same-sex relationship are "always" or "mostly" wrong from 48 per cent of the population in 2000 to just 18 per cent in 2015 (Scottish Government, 2016b). Breaking this down by neighbourhood deprivation quintile, 24.7 per cent of people in the most deprived 20 per cent of neighbourhoods think that same-sex relationships are always or mostly wrong, compared to just 17.4 per cent in the least deprived neighbourhoods in Scotland. The broader debate about why socio-economically disadvantaged, or working class, people have more illiberal attitudes does not directly concern us here. We do feel that it is worth noting the higher prevalence of people openly admitting to being homophobic in deprived neighbourhoods. To compound this, given the social stigma now associated with admitting to socially illiberal attitudes, it has been suggested that attitudes surveys are failing to capture the full extent of such views due to social desirability bias, so there could be under-reporting of these homophobic and transphobic attitudes (Krumpal, 2013).

\section{Housing pathways and the affordances of place}

To understand these processes of residence we employ the theoretical approach of housing pathways. Housing pathways are described as 'the household forms in which individuals participate and the routes they take over time in their experience of housing' (Clapham, 2005: 2). The approach seeks to move away from accounts of housing choice that focus on economic decision-making where it is 'assumed that households are rational and instrumental in their approach to housing decisions' (Clapham, 2002: 10). As an approach, it also contrasts with extant accounts of housing where households are often portrayed as 'the ciphers of structural forces ... they are assumed to have simple and universal attitudes and motives' (Clapham, 2005: 10). As discussed above, this is the case with some scholarship on LGBT+ households, seen as socially, and thus economically excluded, and forced to act as first-wave gentrifiers; and residents of deprived neighbourhoods, who are identified as socially and economically excluded and thus they are living in neighbourhoods subject to disinvestment by governments and markets. Instead of such approaches, housing pathways focuses on the lived experiences of people in their homes and neighbourhoods, the meanings of home to a household, how a home is part of someone's identity and how this changes over time, and finally how the affordances of home differ for different households (Clapham et al., 2017; Clapham, 2002).

A housing pathways approach does not preclude the structural factors that impact on an individual's, or a household's, choices. The analytical approach of housing pathways is particularly useful, we would argue, when analysing data by variables such as sexual or gender identity (or disability, and ethnicity) that, although aligned to socio-economic position or class position, also cut across these categories and intersect with them in complex ways (Uhrig, 2015). If in the late-modern world, housing and home is as much about a 'search for identity and fulfilment through lifestyle choice' (Clapham, 2005: 34) than it is about fulfilling a need for shelter (Savage, 2010; Watt, 2009), 
then a focus on a household's experiences of time, choices, experiences of housing and meanings held, is a fruitful avenue for analysis.

As Clapham (2005) suggests, extending his metaphor of housing pathways, some households travel along motorways along with many others, such as the traditional heterosexual nuclear family in owner-occupied housing; other households travel down small, rarely travelled side lanes, such as disabled people with specific needs or people who have experienced homelessness (Clapham, 2015). We would argue that the "side lane" of LGBT+ households has been relatively rarely travelled by people and researchers due to a small $n$. Most population survey data suggests that nonheterosexual people are around three per cent of the adult population (Scottish Government, 2017b; Office for National Statistics, 2017). ${ }^{2}$ We currently have no reliable statistics on gender identity. We would also suggest that accounts of LGBT+ housing and home have been dominated by economistic accounts, such as those associated with narratives of gentrification, or home as an isolated entity without a neighbourhood context.

The housing pathways approach also focuses us on the affordances that neighbourhoods and home offer to individuals (Clapham 2017), however in a heteronormative society these are often explained around the heterosexual family unit, such as suitable housing to meet family aspirations. A key affordance of home is privacy to be oneself. Historically, for gay people home, particularly the family home, did not offer such affordances (Valentine et al., 2003; Prendergast et al., 2001), although it is important not to over-generalise this point (Gorman-Murray, 2008). If one's home was in a neighbourhood that is not welcoming to your queerness, then this lack of privacy to be oneself may be further compounded. As suggested by Clapham (2015: 35) discussing supported housing in neighbourhoods:

'if the existing neighbourhood is low on affordances, and is either threatening or unpleasant or of low status, then staying in that neighbourhood may not lead to high self-esteem or wellbeing.'

Yet urban and housing research has not fully explored the lived experiences of LGBT+ identifying people in their homes in neighbourhoods that are not "gaybourhoods", with notable exceptions (Ghaziani, 2014; Gorman-Murray, 2006; Valentine et al., 2003). The lived experiences of home of LGBT+ identifying people in marginal neighbourhoods, who have had limited housing choices, remains largely unexplored (although note the narratives of LGB people who live in edge-of-centre neighbourhoods in Atlanta in: Doan and Higgins, 2011).

\section{Methodology}

The fieldwork for this research was carried out from autumn 2016 to summer 2017. The sample was opportunistic by necessity. The small $n$ of the target population and ethical considerations around identifying and "outing" individuals, meant that a larger sample, or one that was representative of a wider population, was impossible within the scope of the research project. The research team sent out a call for participants among the members of an umbrella housing group. This was followed up by direct contacts to housing associations that the research team had contact with, or who were recommended by other participants and connections. Organisations, predominantly housing associations, were asked to display a flyer or distribute it directly to people they knew as identifying as LGBT+. Some housing associations were reluctant to approach people directly, as they felt this was compromising the confidentiality of their service users, even if they were open about their sexual or gender identity. A flyer was also circulated on Facebook, Twitter and in the online news site of a neighbourhood in Edinburgh. Recognising the stigma associated with language such as 
"deprived neighbourhood", and that this is mainly a term used in policy-making, the flyers were geographically tailored with the names of specific neighbourhoods that were in the most deprived 20 per cent of neighbourhoods as measured by the Scottish Index of Multiple Deprivation. Participants found through these routes were also asked to suggest further participants. Finally Matthews created a profile on the dating app for men-who-have-sex-with-men, Grindr, with oversight by his institutional ethics panel. Again, the details about the project were tailored to target specific neighbourhoods as Grindr uses location services to only show profiles near to the user (for more detail on this see: Matthews, 2017). These varied methods of recruitment avoided the problems with bias associated with sampling populations from LGBT+ support organisations (Cimpian, 2017) but we recognise that the sample was opportunistic and not representative.

The sampling strategy aimed to interview LGBT+ people who had either experienced homelessness (a possible route to then living in a deprived neighbourhood) and LGBT+ people who lived in deprived neighbourhoods. At the end of the fieldwork period with an enormous amount of work on recruitment, 20 people had been interviewed. Nominally, 10 people were interviewed because they had experienced homelessness and 10 people because they lived in deprived neighbourhoods. However, there was considerable overlap in the two samples. Following best practice in interviewing homeless people (Kunnen and Martin, 2008) and understanding meanings of place (Matthews, 2012), a narrative interviewing approach was used (Hollway and Jefferson, 2000). The opening question simply asked people where they lived and how they came to be living there. This allowed participants to tell their own story, linking events in their life to where they ended up living. This was followed-up with questions about their experiences of living in the neighbourhood and, if appropriate, their experience of accessing the services of their landlord.

Population-level data for Scotland would put the sample population at around 34,000 individuals 20 per cent of non-straight people live in deprived neighbourhoods, and three per cent of Scotland's population of 5.8 million define themselves as non-straight. Because of this very small population, and the close-knit nature of the community in deprived neighbourhoods, and LGBT+ communities (Formby, 2017) there is a very high risk that participants could be identified. In agreement with our institutional ethics panel and following data protection regulations, we provide very few demographic details for our participants and use the gender descriptors they chose. All participants chose their own pseudonyms.

As well as LGBT+ identifying residents of deprived neighbourhoods, the research also interviewed staff from four different housing associations, of varying size in Glasgow, Renfrewshire and Edinburgh. The research team also led a discussion among housing officers at one housing association about how services might be tailored for LGBT+ service users. All interviews were transcribed and read by both members of the research team and coded in vivo using the qualitative data analysis software Nvivo.

\section{Findings}

The findings are in two sections reflecting the research questions above. In describing how people came to be living in deprived neighbourhoods we identified three themes: extreme vulnerability or disability; an experience of homelessness; or an active choice when people were in less constrained circumstances. These are not discrete categories and there is overlap between them, for example someone's vulnerability could be associated with their experience of homelessness. We then go on to discuss how our participants made home in their neighbourhoods. 
Using a housing pathways approach, we can understand these pathways from the amount of agency individuals had in achieving their current housing situation in different contexts of affordances and structural constraints. In terms of vulnerability or homelessness, participants had very limited choice, or their choices were made for them by support workers. The other, larger group had a greater degree of choice. This may have overlapped with other vulnerabilities, such as a disability, but as the participants described their housing journeys there was a clear agency in their choice to live in an affordable home, that happened to be in a deprived neighbourhood.

\section{Vulnerability}

In total, seven of our participants moved to their current homes in deprived neighbourhoods due to their specific vulnerabilities. These overlapped with other experiences, such as homelessness. For these people, a socially rented home in a deprived neighbourhood was one that they could afford, although often the element of "choice" was limited by their vulnerability, for example a gay man explained:

"My memory of that period is not too clear any more, but I remember it was not a pleasant time. My name was put on the [housing waiting list]. I think someone else did that for me and so I was surprised two years later to get a phone call offering me a house/a flat" (Andy, gay man)

Other participants had confused biographies, including periods of mental illness, and experiences of being taken advantage of by others. A good example of the vulnerabilities experienced by these participants is summarised here:

"I was quite lucky because, obviously, I have certain disabilities - Aspergers, ADHD, fibromyalgia and depression - so I got a [higher] priority and was housed fairly quickly, I was housed within two years" (Dathne, transwoman)

For this woman, her disability meant she needed to access social housing in a deprived neighbourhood, as it offered an affordable home and the support of a housing officer. The complex vulnerabilities experienced by these participants meant that a socially rented home, in a deprived neighbourhood, provided a reasonably positive outcome, but in a situation with limited choices.

\section{Experience of homelessness}

Sexual and gender identity interacts in complex ways with experiences of homelessness, as well as being a direct cause through family rejection (Prendergast et al., 2001; Valentine et al., 2003; Matthews et al., 2018, forthcoming). Four of our participants had experiences of homelessness, either through accessing the statutory homeless system, or who could be classed as homeless by an expansive definition of homelessness (Jacobs et al., 1999; FEANTSA, 2017). For one of these participants, the supported hostel accommodation they were currently living in was in a deprived neighbourhood. Another participant was supported by their homelessness officer to apply for a socially-rented home and was eventually housed in a deprived neighbourhood. The other two cases of homelessness overlap with the next, broader category, of people who moved to a neighbourhood by choice. These were two transwomen, one who needed to move after her relationship ended following transition, and the other who wanted to move for a new start following her transition. Both these participants lived in shared ownership homes (where the occupant owns a proportion through a mortgage, but a proportion is retained by a housing association, for which the resident pays rent, an affordable way to access home-ownership (McKee, 2010)).

\section{Choice}


Seven participants, in six households, had actively chosen to live in their homes in deprived neighbourhoods. These pathways differed from those above in that the agency, for example to apply for a socially rented home by joining a waiting list, was not taken away from these people by the structural constraints in their lives. They can be separated into those who rented their homes from a social landlord, and owner-occupiers.

The broader framing of this paper is that social housing is a marginal tenure, and people with limited housing choices will live in socially rented homes in deprived neighbourhoods solely because they cannot choose to live elsewhere. We must recognise though that many people do choose to stay in socially rented homes. Three households in our research, who had greater choice, were in this category. Two of the households were related, and came from households that had rented their homes from the same social landlord. One of the households summarised their experience as:

"It is a long story really - my sister and my nephew got involved with some very bad people and, basically, my life got threatened so I moved in with my sister and her wife and then got my own flat round here, and moved recently round the corner" (Michael, gay man)

The element of choice was most apparent elsewhere in this participants' narrative - their experience of living with another landlord in another neighbourhood had been very poor, with considerable problems with antisocial behaviour and repairs. Moving to live near their sister, in a socially rented home, was therefore a clear choice to move to a landlord that came personally recommended. Looking across this family's stories, they had also always lived in social rented housing, so moving elsewhere in the city to another socially rented home was normalised in their life experience. This also applied to the other participant who chose to live in a socially rented property in a deprived neighbourhood, who explained that:

"I moved to this scheme in 1995. I stayed in the back end of [deprived neighbourhood] and then moved to here and I have been here ever since." (James, gay man)

The four participants who were homeowners, which include the two transwomen who lived in shared-ownership properties described above, all chose to move to their respective neighbourhoods because of the affordability of the housing. For example, a participant who was a home-owner, explained how she had been single and in a relatively low-paid job (nursing). Prior to the financial crash of 2008, like many, she aspired to home-ownership. Stretching her finances she managed to buy a flat in a deprived neighbourhood that had been bought though he right-to-buy, explaining:

"I wanted to buy somewhere and, at the time the property markets were really, really high (it was 2005), so, in order to get what I wanted within my budget as a single person, I ended up taking out a massive mortgage and ended up living and buying a flat in [deprived neighbourhood] because that was all that was really available to me with my budget." (Tracy, gay woman)

She went onto describe that this was because property prices in the area of the city that was the commercial focus for the gay community had become too high. Arguably, this is an example of the patterns of gentrification associated with heterosexuals moving into gaybourhoods that have led to changing gay residence patterns globally (Ghaziani, 2014; Doan and Higgins, 2011; Nash and Gorman-Murray, 2014).

While income and broader housing market dynamics limited her choices, for this participant, the purchase of this flat was the first rung on the property ladder and she did have the secure income 
and ability to purchase a home through mortgage finance. The participants in shared-ownership properties were also taking advantage of the affordability of homes in deprived neighbourhoods to get a home they could otherwise not afford, as described by one participant:

"When I was looking I saw this place advertised on one of the search engines that I was looking at. I had seen it three times over about a six-week period and at the time during the advert to be eligible to apply for the place you had to earn something up to $£ 32$ or $£ 34,000$ a year...I decided to phone them at the third time I saw it. I said that I kept seeing this place, is there something wrong that nobody is applying for it? She said that no...I came along and saw the place and absolutely fell in love with it and decided to move" (Tony, gay man)

This aligns with the experiences of shared-ownership more broadly, where affordability and the quality of new homes were key aspects that attracted people to the tenure (McKee, 2010).

From these three pathways identified from our participants for how they came to be living in a deprived neighbourhood, it is arguable that sexual or gender identity did not play a direct role in their housing choices (or lack of choice). Vulnerable disabled people are also likely to access sociallyrented housing, which is likely to be in deprived neighbourhoods whether they identify as LGBT+ or not (Clapham, 2015). However, to return to the premise of this paper and research, we know that a disproportionate number of non-straight people live in Scotland's most deprived neighbourhoods. Therefore, we can surmise that the housing pathways above, most probably homelessness and having a lower-income due to greater likelihood of being a single-person household, are more common among non-heterosexual households.

\section{Exclusion from housing}

As previously mentioned, statutory rights for homeless people in Scotland are expansive. This differs from the legal situation elsewhere in the UK during the period of the research where only people with 'priority need' (in summary, households with children; disabilities or other vulnerabilities; victims of domestic violence; or people who were in poor quality or overcrowded housing) had a statutory right to housing. The limited research on LGBT+ homelessness in England and Wales suggests priority need was a way heteronormativity and homophobic bias created discrimination in homelessness services. For example, a participant in Tunåker's research (2017) was declared intentionally homeless (and thus not due support) because he had been ejected from the family home after coming out; his act of coming out was judged to be a "choice" to become homeless by the housing authority. Such discrimination should not happen in Scotland and we found no evidence of it in this research, but we did find evidence it had been used historically, as described by Michael (gay man):

"I put my name down for the housing round here [in a deprived neighbourhood with social housing]. I was told I had no points; I had no priority; I had no kids; I had nothing, so it was accept it, deal with it and move on."

Even though priority need as a legal category has been abolished in Scotland, local housing authorities still prioritise some households, particularly those with children or disabled people, in housing allocations. The awareness of this aspect of housing allocations was described by this participant: 
"I know that if I applied to the Council for a council house I would be bottom of the list because I do not have any children. In a way, I get that because children are important" (Daniel, gay man)

This statement also represented an understandable internalised heteronormativity on his part. He recognised the specific housing needs of households with children, who are more likely to be heterosexual, as being important. However, he followed this logic to the extent that he downplayed his own need and vulnerability - he "got" it. He continued to discuss how some single, LGBT+ people are extremely vulnerable and, although they may have different needs to a family with children, they still have housing needs. It is at moments such as this that we see the interaction of compulsory heterosexuality in society and housing policy, where a man in housing need downplayed that need with internalised homophobia (Tunåker, 2017).

\section{Making home in a deprived neighbourhood}

We will now discuss our participants' experiences of living in a deprived neighbourhood. Unfortunately their experiences of living in deprived neighbourhoods were often tinged with a fear that they might be victims of hate crime or aggression. Both Jess and Tony described how they took precautions at night in their neighbourhoods:

"I do not like to go out at night time. That is the only time I would say that I feel unsafe. I do not go out in the dark. I do not feel safe coming back from the city centre on a bus in the evening. I used to do that, but not anymore." (Jess, transwoman)

"If I am out with friends at a nightclub, you are talking after one/two in the morning, if I am coming home then, rather than getting a taxi to drop me off [a distance away and] walking down, I will get it to come up and drop me off at the back door... I try to be a bit more sensible that way." (Tony, gay man)

For Tracy, this emerged when she was asked if she thought her experiences would be different if she were heterosexual, and she suggested that "[m]y public persona in the area will always be quieter than if I was straight" and that she was less likely to display affection with her partner in public. This narratives echoed the negative experiences of gender-variant people highlighted in previous research (Namaste, 1996) and the tactics and strategies used to avoid harassment or violence (Namaste, 1996; Doan, 2010).

The close-knit communities of deprived neighbourhoods was also recognised as a problem because of the resulting lack of anonymity. For example, participants were aware that the local community knew the nature of the housing stock in detail, so if two people of the same sex were living in a onebedroomed property, they were automatically outed to their neighbours. Other participants experienced violence or upsetting incidents because of their sexual or gender identity, including one transwoman who had all the windows in her flat, except one, smashed by local young people who were shouting transphobic abuse. It should be noted that all of our small sample of transgender participants had experienced some sort of homophobic or transphobic abuse. This suggests that while overt homophobia has reduced in society, transphobia is still a problem.

Other negative experiences of our participants were not directly associated with their sexual or gender identity and more related to living in a deprived neighbourhood: problems with youth antisocial behaviour, drug and alcohol abuse and low-level criminality. These varied from quite violent incidents to disruptive antisocial behaviour: 
"there is fighting and people partying all hours of the day and night. Somebody got stabbed right outside the front door" (Michael, gay man)

"it was a neighbour who was quite disruptive, noisy and organised parties early in the morning" (Daniel, gay man)

These incidents should not be dismissed as just inconveniences for these residents; they could be distressing and add to anxiety about living in a neighbourhood and are paralleled by UK-wide research (King, 2018). The owner-occupier who had chosen to buy a property in a deprived neighbourhood, explained that:

"The flat opposite me is a temporary housing association flat...that had the drug dealer...I was stressed and anxious when that drug addict/dealer lived there" (Tracy, gay woman)

Other reported incidents included graffiti that could be interpreted as being against specific residents (a penis being drawn on a car outside the house of a transwoman), theft and vandalism.

While recognising these negative experiences, here we also want to highlight the more positive experiences of residents. A lot of the experiences of service provision and residence were universal: housing officer support; responsive repairs and maintenance; and the nature of the neighbourhood and neighbours. For tenants of social landlords, or people in shared ownership properties, the mundane interactions of service delivery were handled professionally, recognising diversity, such as using the appropriate pronouns for a transwoman:

"If I need repairs done, the repairs get done and stuff like that." (Andy, gay man)

"on a day to day interaction with them it is all fine: proper pronouns and everything" (Jess, transwoman)

There was also a recognition that the housing services delivered by housing associations were excellent, especially support to tenants with extra needs:

"the housing officer will just pop over. She will give you a phone and ask if you are free for a chat. They are happy to come to you or you to go them, whichever you are more comfortable with. They will update you and tell you what is going on and where you stand and make sure that you are okay." (Sadie and Doddy, gay women)

Participants were also positive about their communities and found them welcoming. One participant had lived in a different deprived neighbourhood in the city prior to moving to their current flat and explained how:

"The flat that I have out in [other deprived neighbourhood] (the high rise flat), I was on the ground floor and I worked in one of the roughest pubs out in that area, and they all knew about me - no, they did not care." (Bob, gay man)

Other participants enjoyed the strong sense of community in their neighbourhoods, recognising that it could offer protection and support. Michael described how: "For being a deprived area, everybody knows everybody and everybody's business." Tony enjoyed the fact that people would stop to talk to him in his neighbourhood:

"standing at a bus stop, people talk, especially in Scotland. People will talk to you. You walk down the street - hello, hello. Not that I have that much of a garden, but when I have been putting plant pots out at the front with, one of benches, my wee flower 
box/bed at the front at the window, some of the neighbours go past and will stop, say hello, have a chat" (Tony, gay man)

For Tracy (gay woman), it took time to feel welcome in her neighbourhood, where she was now involved in a number of community groups. As she explained:

"I think I had to live in the area for a good ten years before I felt that I could be [open], and then the community kind of gets to know you once you seem familiar, sort of keep their eye on your car for you. From being quite horrific at the start and probably one of the worst choices buying this flat in an area that you know does not really fit in with your lifestyle at all to now - I actually quite like the place - I am actually quite part of the community."

The other positive aspects of neighbourhoods noted by participants often related to regeneration policy interventions that provided enhanced services: new housing and an improved local environment; affordable local services, like health clubs and social activities; community activities such as community gardening and arts and crafts. These all meant our participants could take positive meanings from the home, and the neighbourhood, they had ended up living in.

\section{Negotiating external meanings}

While having positive internal experiences of their neighbourhoods, and drawing positive meanings, from these, our participants also recognised that they had to negotiate the negative stigma associated with living in a deprived neighbourhood, and the misconception from wider society that "we are all sponging off the social" (Michael). All our participants were, to use the typology developed by Dean and Hastings (2000: 8), committed residents: 'These are residents who choose to stay. They are typically long-standing residents, well connected within the estate, regularly using its facilities, and are family-oriented.'

However, as we have seen from Tracy's story, this was often from a position of being more ambivalent about a neighbourhood until they came to know about it more. The positive qualities of the neighbourhood, and becoming embedded in the local community meant that after living in her neighbourhood for over a decade she could say:

"I am a fan of the area. It is not pretty, but I have lived here now for twelve years and if a white, English lesbian can get accepted in [neighbourhood] then it is really not a bad thing."

Yet, the acknowledgement of the everyday deprivations of living in such a neighbourhood did mean some of the positive attitudes were tinged with a selective belonging - recognising a positive affiliation with a neighbourhood, but disaffiliating from the negative aspects (Watt, 2009; Matthews, 2015). Participants spoke of the stigma they experienced from wider society: "a lot of people say to me, you are living in [neighbourhood], that is a dive" (Bob, gay man) and negotiating this when forming new relationships: "There was a time I would say to friends, my god, even if I fancy anybody and by the way I live in [neighbourhood] - that would be a real turnoff" (Andy, gay man). Such experiences were very different from the welcoming homonormativity of suburban life (Ghaziani, 2014) or the home as an extension of the gay scene (Gorman-Murray, 2006).

\section{Conclusion}

This paper has sought to bring new stories into our understanding of deprived neighbourhoods, and the lives of people who identify as LGBT+. The LGBT+ people in our study found themselves living in 
deprived neighbourhoods through a variety of routes, many of which will be paralleled by experiences in the non-LGBT+ population. All our participants had limited housing choices due to their individual circumstances. Some had no choice and needed the social housing in a deprived to meet an immediate housing need. Others had their choices for good housing expanded by the affordability offered by the cheaper housing available in a deprived neighbourhood. The housing pathways approach we used revealed the ways in which our participants' housing experiences were affected by the limited affordances of their neighbourhoods. Many of these were negative: experiences of fear and threat; antisocial behaviour and criminality; and the stigma associated with living in a deprived neighbourhood. This was countered by more positive attitudes and a sense of commitment to the neighbourhood. It is important to note this may have been due to the selfselecting nature of the sample - most participants had responded positively to a request to speak to people living in a deprived neighbourhood, and people who were less content with their housing situation may have chosen not to participate.

The paper also demonstrates the importance of bringing in the lives and experiences of LGBT+ people as a category of analysis into more mainstream urban research - in this case research into neighbourhood deprivation. While our participants found home in deprived neighbourhoods, such neighbourhoods were also places of fear, where ones' embodied sexual or gender identity had to be closeted for protection - people walked with their heads down, or avoided holding hands with their partners. While existing research goes into great detail about the negative and positive aspects of residence in a deprived neighbourhood for everyone, the difference that sexual and gender identity brings to residents' experiences has largely been ignored.

By focusing on stories from households with limited housing choices in their housing pathways, who lived in deprived neighbourhoods, we also offer an alternative perspective on LGBT+ residence. We move the attention away from LGBT+ people, and particularly white, gay men, as being "gentrifiers par excellence" (Gorman-Murray, 2006: 66). Data from the UK shows that non-heterosexual men and women are less likely to have a mortgage than their heterosexual counterparts (Uhrig, 2015) and as noted above, the fact that a disproportionate number of non-heterosexuals live in the most deprived neighbourhoods in Scotland was the inspiration for this research. This suggests that, following the class-based critiques of much social research on sexual and gender identity (for example: Taylor, 2008) urban research needs to more fully explore the experience of LGBT+ people across our towns and cities, and not just in traditional and high-profile "gaybourhoods". This would enrich our understanding of such neighbourhoods, and the lives of their residents, and our understanding of more marginalised people who identify as LGBT+.

\section{References}

Andersson J. (2019, online preprint) Homonormative aesthetics: AIDS and 'de-generational unremembering' in 1990s London. Urban Studies doi: 10.1177/0042098018806149.

Bailey N and Livingston M. (2008) Selective migration and area deprivation: evidence from 2001 Census migration data for England and Scotland. Urban Studies 45: 943-961.

Browne K. (2010) Queer quantification or queer(y)ing quantification: Creating lesbian, gay, bisexual or heterosexual citizens through governmental social research. In: Browne K and Nash C, J. (eds) Queer Methods and Methodologies: Intersecting Queer Theories and Social Science Research. Farnham: Ashgate, 231-250.

Castells M. (1983) The City and the Grassroots, Berkeley: University of California Press.

Cheshire P. (2009) Policies for Mixed Communities. International Regional Science Review 32: 343375. 
Cimpian JR. (2017) Classification Errors and Bias Regarding Research on Sexual Minority Youths. Educational Researcher 46: 517-529.

Clapham D. (2002) Housing Pathways: A Post Modern Analytical Framework. Housing, Theory and Society 19: 57-68.

Clapham D. (2005) The Meaning of Housing: A pathways approach, Bristol: The Policy Press.

Clapham D. (2015) Accommodating Difference: Evaluating Supported Housing for Vulnerable People, Bristol: Policy Press.

Clapham D, Foye C and Christian J. (2017) The Concept of Subjective Well-being in Housing Research. Housing, Theory and Society: 1-20.

Dean J and Hastings A. (2000) Challenging Images: Housing Estates, Stigma and Regeneration, Bristol: Policy Press.

Dekker K and Van Kempen R. (2004) Large housing estates in Europe: current situation and developments. Tijdschrift voor Economische en Sociale Geografie 95: 570-577.

Doan PL. (2010) The tyranny of gendered spaces - reflections from beyond the gender dichotomy. Gender, Place \& Culture 17: 635-654.

Doan PL and Higgins H. (2011) The Demise of Queer Space? Resurgent Gentrification and the Assimilation of LGBT Neighborhoods. Journal of Planning Education and Research 31: 6-25.

Donovan C, Heaphy B and Weeks J. (2004) Same Sex Intimacies: Families of Choice and Other Life Experiments, London: Taylor \& Francis.

Ecker J. (2016) Queer, young, and homeless: A review of the literature. Child \& Youth Services 37: 325-361.

FEANTSA. (2017) European Typology on Homelessness and Housing Exclusion, https://www.feantsa.org/en/toolkit/2005/04/01/ethos-typology-on-homelessness-andhousing-exclusion: (accessed 29 October 2018).

Florida R and Mellander C. (2010) There goes the metro: how and why bohemians, artists and gays affect regional housing values. Journal of Economic Geography 10: 167-188.

Formby E. (2017) Exploring LGBT Spaces and Communities: Contrasting identities, belongings and wellbeing, Abingdon: Routledge.

Galster G, Quercia RG and Cortes A. (2000) Identifying neighborhood thresholds: an empirical exploration. Housing Policy Debate 11: 701-732.

Ghaziani A. (2014) There Goes the Gayborhood?, Princeton, NJ: Princeton University Press.

Gorman-Murray A. (2006) Homeboys: uses of home by gay Australian men. Social \& Cultural Geography 7: 53-69.

Gorman-Murray A. (2008) Queering the family home: narratives from gay, lesbian and bisexual youth coming out in supportive family homes in Australia. Gender, Place \& Culture 15: 31-44.

Hall P. (1997) Regeneration policies for peripheral housing estates: inward- and outward-looking approaches. Urban Studies 34: 873-890.

Hollway W and Jefferson T. (2000) Doing Qualitative Research Differently: Free Association, Narrative and the Interview Method, London: Sage.

Jacobs K, Kemeny J and Manzi T. (1999) The struggle to define homelessness: a constructivist approach. In: Hutson S and Clapham D (eds) Homelessness: Public Policies and Private Troubles,. London: Cassell, 11-28.

King A. (2018) No Place like Home? Exploring the concerns, preferences and experiences of $L G B T^{*} Q$ social housing residents, Guildford: University of Surrey/HouseProud.

Krumpal I. (2013) Determinants of social desirability bias in sensitive surveys: a literature review. Quality \& Quantity 47: 2025-2047.

Kunnen N and Martin R. (2008) Chapter 3 Reinterpreting the research path: using qualitative methods in homelessness research. In: Maginn PJ, Tonts $\mathrm{M}$ and Thompson SM (eds) Qualitative Housing Analysis: An International Perspective. Bradford: Emerald Group Publishing, 61-89. 
Lauria M and Knopp L. (1985) Toward an Analysis of the Role of Gay Communities in the Urban Renaissance Urban Geography 6: 152-169.

Lawless P. (2011) Understanding the scale and nature of outcome change in area-regeneration programmes: evidence from the New Deal for Communities programme in England. Environment and Planning C: Government and Policy 29: 520-532.

Matthews P. (2012) From area-based initiatives to strategic partnerships: have we lost the meaning of regeneration? Environment and Planning C: Government and Policy 30: 147-161.

Matthews P. (2015) Neighbourhood Belonging, Social Class and Social Media - Providing Ladders to the Cloud. Housing Studies 30: 22-39.

Matthews P and Besemer K. (2015) The "Pink Pound" in the "Gaybourhood"? Neighbourhood Deprivation and Sexual Orientation in Scotland. Housing, Theory and Society 32: 94-111.

Matthews P, Poyner C and Kjellgren R. (2018, forthcoming) Lesbian, gay, bisexual, transgender and queer experiences of homelessness and identity: insecurity and home(o)normativity. International Journal of Housing Policy.

McKee K. (2010) Promoting homeownership at the at the margins: the experience of low-cost homeownership purchasers in regeneration areas. People, Place \& Policy Online 4: 38-49.

Mercer CH, Tanton C, Prah P, et al. (2013) Changes in sexual attitudes and lifestyles in Britain through the life course and over time: findings from the National Surveys of Sexual Attitudes and Lifestyles (Natsal). The Lancet 382: 1781-1794.

Namaste K. (1996) Genderbashing: Sexuality, Gender, and the Regulation of Public Space. Environment and Planning D: Society and Space 14: 221-240.

Nash CJ and Gorman-Murray A. (2014) LGBT Neighbourhoods and 'New Mobilities': Towards Understanding Transformations in Sexual and Gendered Urban Landscapes. International Journal of Urban and Regional Research 38: 756-772.

Noble M, Wright G, Smith G, et al. (2006) Measuring multiple deprivation at the small-area level. Environment and Planning A 38: 169-185.

Office for National Statistics. (2017) Lesbian, gay, and bisexual people say they experience a lower quality of life: http://visual.ons.gov.uk/lesbian-gay-and-bisexual-people-say-theyexperience-a-lower-quality-of-life/ (accessed 8 August 2017).

Pilkey B. (2014) Queering heteronormativity at home: older gay Londoners and the negotiation of domestic materiality. Gender, Place \& Culture 21: 1142-1157.

Prendergast S, Dunne GA and Telford D. (2001) A story of "difference", a different story: young homeless lesbian, gay and bisexual people. International Journal of Sociology and Social Policy 21: 64-91.

Rae A. (2012) Spatially Concentrated Deprivation in England: An Empirical Assessment. Regional Studies 46: 1183-1199.

Rivers I and Cowie H. (2006) Bullying and Homophobia in UK Schools: A Perspective on Factors Affecting Resilience and Recovery. Journal of Gay \& Lesbian Issues in Education 3: 11-43.

Robson B, Lymperopoulou K and Rae A. (2008) People on the move: exploring the functional roles of deprived neighbourhoods. Environment and Planning A 40: 2693-2714.

Savage M. (2010) Class and elective belonging. Housing, Theory and Society 27: 115-136.

Scottish Executive. (2005) Social Focus on Deprived Areas, Edinburgh: Scottish Executive.

Scottish Government. (2016a) Introducing The Scottish Index of Multiple Deprivation 2016 Edinburgh: The Scottish Government.

Scottish Government. (2016b) Scottish Social Attitudes 2015: Attitudes to discrimination and positive action, Edinburgh: The Scottish Government.

Scottish Government. (2017a) Scotland's People Annual report: results from 2016 Scottish Household Survey, Edinburgh: The Scottish Government.

Scottish Government. (2017b) Sexual Orientation in Scotland 2017: A Summary of the Evidence Base, Edinburgh: The Scottish Government (http://www.gov.scot/Resource/0051/00513240.pdf). 
Slater T. (2013) Your Life Chances Affect Where You Live: A Critique of the 'Cottage Industry' of Neighbourhood Effects Research. International Journal of Urban and Regional Research 37: 367-387.

Taylor Y. (2008) 'That's Not Really My Scene': Working-Class Lesbians In (and Out of) Place. Sexualities 11: 523-546.

Tunåker C. (2017) The Paradox of Progress, Unpublished PhD Thesis, University of Kent.

Tunstall R and Coulter A. (2006) Twenty-Five Years on Twenty Estates: Turning the Tide? York: Joseph Rowntree Foundation.

Tunstall R and Lupton R. (2010) Mixed Communities: Evidence Review, London: Communities and Local Government.

Uhrig SN. (2015) Sexual Orientation and Poverty in the UK: A Review and Top-Line Findings from the UK Household Longitudinal Study. Journal of Research in Gender Studies 5: 23-72.

Valentine G, Skelton T and Butler R. (2003) Coming Out and Outcomes: Negotiating Lesbian and Gay Identities With, and in, the Family. Environment and Planning D: Society and Space 21: 479499.

Wacquant L. (2008) Urban Outcasts: A Comparative Sociology if Advanced Marginality, Cambridge: Polity Press.

Watt P. (2009) Living in an oasis: middle-class disaffiliation and selective belonging in an English suburb. Environment and Planning A 41: 2874-2892.

Watts B. (2014) Homelessness, Empowerment and Self-reliance in Scotland and Ireland: The Impact of Legal Rights to Housing for Homeless People. Journal of Social Policy 43: 793-810.

\footnotetext{
${ }^{1}$ We use the acronym LGBT+ in this context as it is the widely accepted acronym used by representative organisations in Scotland, and encompasses non-binary, intersex and queer identifying people.

${ }^{2}$ Although it should be noted that a far greater proportion of the population have had same-sex sexual experience or have same-sex sexual attraction Mercer CH, Tanton C, Prah P, et al. (2013) Changes in sexual attitudes and lifestyles in Britain through the life course and over time: findings from the National Surveys of Sexual Attitudes and Lifestyles (Natsal). The Lancet 382: 1781-1794. this is a key problem with applying essentialist categories onto queer bodies Browne K. (2010) Queer quantification or queer(y)ing quantification: Creating lesbian, gay, bisexual or heterosexual citizens through governmental social research. In: Browne $\mathrm{K}$ and Nash C, J. (eds) Queer Methods and Methodologies: Intersecting Queer Theories and Social Science Research. Farnham: Ashgate, 231-250.
} 